\title{
The Distribution of Total Petroleum Hydrocarbons Categories in Kolo Creek, Niger Delta, Nigeria
}

\author{
EDORI, E. S..$^{1 *}$, BEKEE, D. ${ }^{2}$, IGWE, P. U. ${ }^{3}$ \\ ${ }^{1}$ Department of Chemistry, Ignatius Ajuru University of Education Rumoulumeni, Port Harcourt, Rivers State, \\ Nigeria \\ ${ }^{2}$ Department of Chemistry, Rivers State University, Port Harcourt, Rivers State, Nigeria \\ ${ }^{3}$ Evomec Global Services Limited, 50A GRA Phase 2, Port Harcourt, Rivers State, Nigeria
}

*Corresponding Author: Edori Enize Simeon, Department of Chemistry, Ignatius Ajuru University of Education, Rumuolumeni, Port Harcourt, Rivers State, Nigeria

\begin{abstract}
The degree of contamination by total petroleum hydrocarbons was investigated in Kolo Creek for four months in three different stations. The level of contamination by the hydrocarbon categories: gasoline range organics $(G R O)$, diesel range organics $(D R O)$ and lube oil range in the surface water and sediments of the creek were investigated along the coast. Glass bottles thoroughly washed with dichloromethane were used to collect both samples and treated using standard procedures. Extraction of the hydrocarbons from the samples were achieved through the use of standard methods and the analysis of the samples were performed by the use of GC-FID to determine the concentration of the total petroleum hydrocarbon categories in the samples. The results of the investigations revealed that, GRO was within not detected to $1.148 \pm 0.031 \mathrm{mg} / \mathrm{L}$, DRO, $7.627 \pm 0.7836$ to $15.375 \pm 3.2643 \mathrm{mg} / \mathrm{L}$ and lube oil range, $1.267 \pm 0.1244$ to $3.973 \pm 0.516 \mathrm{mg} / \mathrm{L}$ in the stations and $G R O$, not detected to $1.531 \pm 0.16 \mathrm{mg} / \mathrm{L}, \mathrm{DRO}, 6.783 \pm 1.486$ to $21.213 \pm 5.762 \mathrm{mg} / \mathrm{L}$ and lube oil range, 0.207 \pm 0.0115 to $3.948 \pm 0.9 \mathrm{mg} / \mathrm{L}$ in the months. In the sediments of the creek, concentration values of the categories were $G R O, 1.8961 \pm 0.196$ to $5.4995 \pm 2.036 \mathrm{mg} / \mathrm{Kg}, \mathrm{DRO}, 30.2902 \pm 8.5931$ to $39.8561 \pm 11.0281 \mathrm{mg} / \mathrm{Kg}$ and lube oil range, $0.5564 \pm 0.046$ to $6.2071 \pm 1.43 \mathrm{mg} / \mathrm{Kg}$ in the stations and in the months, GRO,0.2377 \pm 0.01 to $8.2759 \pm 3.01 \mathrm{mg} / \mathrm{Kg}, \mathrm{DRO}, 23.1699 \pm 5.5295$ to $51.2889 \pm 18.0216 \mathrm{mg} / \mathrm{Kg}$ and lube oil range, not detected to $9.7926 \pm 3.252 \mathrm{mg} / \mathrm{Kg}$. The mean concentration values in percentages for the different stations were, GRO, 4.50, DRO, 78.10 and lube oil range, 1.40, in the months, GRO, 6.55, DRO, 77.85, lube oil range, 15.60 for the surface water. In the sediments, GRO, 7.72, DRO, 83.86 and lube oil range, 8.42 in the stations, while in the months, GRO, 6.50, DRO, 79.85 and lube oil range, 13.65. the level of contamination of the creek call for immediate remediation work in order to forestall impending danger due to petroleum hydrocarbon pollution. Keywords: Kolo Creek, hydrocarbon categories, environmental pollution, sediments, surface water
\end{abstract}

\section{INTRODUCTION}

The importance of water cannot be overemphasized in the life of man and his activities. Water (surface and underground) is useful in agricultural, industrial, social, economic and even politic is useful in agricultural, industrial, social, economic and even political development of man and his environment. But due to an uncontrolled and selfish will of man, this natural resource has been perturbed. The perturbation of the natural water bodies such as rivers, lakes, creeks, estuaries, seas and even groundwater is brought about as a result of contaminations being introduced into the water environment as a result of increased technology, population growth, industrialization, agriculture, oil exploration, production and exploitation, domestic wastes (Emongere et al., 2005, Lima et al., 2008) and even greed on the part of man has affected or contributed enormously to the poor water quality experienced in the Niger Delta Region of South South Nigeria.

One of the main ways through which pollution occurs in the Niger Delta rivers is by petroleum exploration exploitation and transportation processes. The discharge of petroleum products into the rivers and creeks has brought about degradation and deterioration of the environment and also has led to changes in the cultural life of the people and has created a lot of social and economic problems (Ite, 2012, Linden and Palsson, 2013, Ite et al., 2016), which often results in communal conflicts within a community or with a neigbouring community. The level at which petroleum hydrocarbons have contaminated the rivers and creeks of the Niger Delta Area has brought about less fishing and 
recreational activities like fishing festivals in the creeks and lakes of the region (Nduka and Orisakwe, 2010). The abundance of petroleum induced chemical wastes which arose due to under-utilization and improper disposal methods of petroleum products, culture of the inhabitants of the region and even the oil companies has impacted negatively on the ecological system and human life within the region (Nnadozie, 2003, Ite et al., 2013).

The spread of environmental pollution and contamination of total petroleum hydrocarbons is due to the high demand of petroleum end products like diesel, kerosene, gasoline, lubricating oil, fuel oil and asphalt (Moslen and Miebaka, 2017). Human activities that has resulted in the increased presence of hydrocarbon pollution includes; gas flaring or aerial deposition, direct dumping of petroleum hydrocarbon products into the creeks, rivers and even oceans, oil bunkering and illegal refining sites which are common in the creeks and estuaries of the region has resulted in the pollution and contamination of the waters of the region and also has reduced the very essence of livelihood of the inhabitants (ATSDR, 1999, Moslen and Miebaka, 2017). The rivers and creeks inhabit a lot of living organisms and the sediment which is the habitat of a great number of aquatic lives acts as a reservoir of pollutants, total petroleum hydrocarbons inclusive and thereby sustains greater risk of accumulation (Sakari et al., 2012). Pollution that is due to petroleum hydrocarbons affects the growth and development of water dwelling organisms (Moslen and Miebaka, 2016) and at critical stages, fishes and other edible aquatic organisms like crustaceans and molluscs marketability reduces as a result of objectionable odour acquired due to pollution and sometimes lead to death animals and plants which are the original inhabitants of the rivers, lakes and estuaries of the region (Dambo, 1992).

This research work is aimed at providing the total petroleum content of the Kolo Creek. The study sought to provide the level of concentration of total petroleum hydrocarbons categories in the surface water and sediments of Kolo Creek in three stations over a period of four months.

\section{MATERIALS AND Methods}

\subsection{Study Area and Location}

The study area covers the Engenni axis of Kolo Creek. Engenni is in Ahoada West Local Government Area of Rivers State, in the Niger Delta area of South South Nigeria. The Kolo Creek is a tributary of Orashi River and starts from Okarki, in Engenni and run through Ogbia Local Government Area of Bayelsa State. The samples were taken at the points $4^{\circ} 58^{\prime} 53.1^{\prime \prime} \mathrm{N}, 6^{\circ} 25^{\prime} 52.6^{\prime \prime} \mathrm{E}$ and $4^{\circ} 57^{\prime} 26.3^{\prime \prime} \mathrm{N}$, $6^{\circ} 26^{\prime} 10.3$ 'E along the Engenni Axis of the creek coast. The inhabitants of Engenni are mainly peoccupied by fishing and farming. There are number of activities that take place within the Engenni Axis of the Kolo Creek which includes, oil exploration and production, illegal oil bunkering, boat transportation, etc. Oil production facilities that belongs to multi-national oil companies includes flow stations, oil fields, gas plants, which has constantly led to the contamination of these rivers. The environmental impact and pollution due to oil exploitation and production over the years in this region have been a source of worry for the inhabitants. Other activities that are predominant in the Kolo Creek apart from oil production includes fishing, sand mining and recreational activities (such as swimming and canoeing).

\subsection{Collection of Water Sample}

Water samples were collected from three different locations from the Engenni axis of Kolo Creek with glass bottles. The glass bottles were thoroughly washed with dichloromethare in order to prevent contamination with the sample of water collected. In each station, water samples were collected at three different points $40 \mathrm{~cm}$ deep and then mixed together to form a single sample that represents sample collected in that particular station. Into the water sample $2 \mathrm{ml}$ of $0.2 \mathrm{~m} \mathrm{H}_{2} \mathrm{SO}_{4}$ was added to bring the $\mathrm{pH}$ of the sample to 2. Sterile pieces of aluminium foil was used in covering the bottle in preventing contamination and harm of the collected sample and the bottle thereafter tightly covered with the help of plastic screw. In order to keep the water sample at a temperature of $4^{\circ} \mathrm{C}$, the sample bottles were then preserved in an ice packed cooler before being transported to The Chemistry Laboratory of the Ignatius Ajuru University of Education for pre-treatment and analysis (Ikpe et al., 2016)

\subsection{Collection of Sediment Sample}

Sediment samples were collected at three different stations of Kolo Creek, from the top few centimeters deep. Representative bulk samples of the sediment in any given location or station were formed by the mixing together of three points sediments collected at random in that station. The samples were 
collected with the aid of a hand held, van veen grab and then transferred to glass bottles previously washed and treated as above before being transported to the laboratory for analysis. The sediment samples collected were preserved and treated as in the case of water samples.

\subsection{Extraction of Water Samples for Total Petroleum Hydrocarbon Determination}

Filtered water samples were then subjected to extraction processes through the aid of a separatory funnel. Different volumes of water samples collected from different stations of Kolo Creek were extracted into a glass separatory funnel of two liters (2L) by volume and filtered with a glass stopper. The solvent used in the extraction processes was $30 \mathrm{ml}$ dichloromethane. In order to allow the organic layer to separate itself completely from the aqueous layer, the separatory funnel was thoroughly shaken for about 5 minutes. To remove water a $5 \mathrm{~g}$ of anhydrous sodium sulphate salt was mixed with the extract (lower layer). The extracted sample was then collected into an already beaker with the use of a filter paper. Then the filtrate was allowed to evaporate under room temperature conditions in a fume cupboard. The filtrate was allowed to be concentrated to $3 \mathrm{ml}$. the extraction procedure was done repeatedly three times for each given sample collected (LAWI, 2011).

\subsection{Extraction of Sediment Sample for Total Petroleum Hydrocarbon Determination}

An analytical weighing balance was used to weigh $10 \mathrm{~g}$ of weighed sediment sample was transferred into an amber bottle. Then $5 \mathrm{~g}$ of anhydrous sodium sulphate $\left(\mathrm{Na}_{2} \mathrm{SO}_{4}\right)$ was measured and put into the amber glass bottle that contains the sediment sample, and then the sediment sample is shaken vigorously for effective mixing of particles. Anhydrous sodium sulphate was added in order to reduce moisture content of the sediment sample. After thorough mixing by shaking of the sediment sample, $30 \mathrm{ml}$ dichloromethane as an extracting solvent was then added to the sample for separation to take place. A tightly closed amber bottle was used in the transfer of the sample to a mechanical shaker after dichloromethane has been added and then agitated under room temperature conditions, and the extracted sediment sample allowed to settle for at least a $1 \mathrm{hr}$ interval. The sediment sample was then filtered with a $110 \mathrm{~mm}$ size filter paper into a beaker previously cleaned for that purpose that has a board on it, the filtrate of the sediment sample was then allowed to concentrate to $1 \mathrm{ml}$ through evaporation (LAWI, 2011).

\subsection{Procedure for Sample Clean Up}

The preparation of the column was performed by the introduction of glass-wool into an already prepared and washed chromatographic column. Then silica gel was introduced into a previously clean beaker. Addition slurry was then introduced into chromatographic column. An Anhydrous sodium sulphate was added into the column then the addition of pentane thereafter. In a previously cleaned beaker, the sample that was concentrated was mixed with cyclohexane was then introduced into the column that was already prepared. The sample was being eluted with pentane and then collected into the beaker below the column and further elution of the sample was carried out with the introduction of more pentane, after the column was properly rinsed with dichloromethane to prevent contamination. The already prepared sample was then allowed to stand firmly in a cupboard after elution of the agitated sample at room temperature for evaporation to take place and proceed for detection. (LAWI, 2011).

\subsection{Separation and Detection of Sample by GC-FID}

The detection of total petroleum hydrocarbons in the water and sediment samples at the various stations of the area under investigation was achieved by the aid of Agilent $5890 \mathrm{~N}$ gas chromatography-flame ionization detector (GC-FID) (Cortes et al., 2012). The sample was concentrated to $3 \mathrm{ml}$ and then injected into the gas chromatography vial for the cleaning of the GC-FID syringe, and an already prepared blank dichloromethane was injected into micro-syringe of the gas chromatography. In order to obtain a good result, the micro syringe was cleaned three time before the analysis of the sample was done. The sample was used to rinse the micro-syringe after which the sample was then injected into the syringe for the total separation of the different compounds or components of the sample. After total separation of compounds in the sample, the amount of total petroleum hydrocarbon content that was being resolved at a particular chromatogram was then measured in $\mathrm{mg} / \mathrm{Kg}$ for the sediment sample and $\mathrm{mg} / \mathrm{L}$ for water sample

\section{RESULTS AND DISCUSSION}

The results recorded for the concentrations of the different categories of total petroleum hydrocarbons in the surface water of Kolo Creek are presented in Tables 1. In Table 1, the concentration values 
obtained for the different total petroleum hydrocarbons categories in the stations of Kolo Creek were, gasoline range organic (GRO); not detected, $1.148 \pm 0.031$ and $0.795 \pm 0.012 \mathrm{mg} / \mathrm{L}$ for stations 1,2 and 3 respectively; diesel range organic (DRO); $12.432 \pm 2.2963,7.627 \pm 0.7836$ and $15.375 \pm 3.2643 \mathrm{mg} / \mathrm{L}$ for stations 1,2 and 3 respectively and lube oil range; $1.267 \pm 0.1244,3.973 \pm 0.516$ and $2.165 \pm 0.5564$ $\mathrm{mg} / \mathrm{L}$ for stations 1, 2 and 3 respectively. The recorded concentration values of total petroleum hydrocarbons in the surface water for the stations of Kolo Creek were GRO; $0.6477 \pm 0.0143 \mathrm{mg} / \mathrm{L}$, DRO; $11.8113 \pm 2.1147 \mathrm{mg} / \mathrm{L}$ and lube oil range; $2.4683 \pm 0.3989 \mathrm{mg} / \mathrm{L}$. In the months under investigation, the average concentration values obtained for GRO were $1.228 \pm 0.074$ and $1.531 \pm 0.16$ $\mathrm{mg} / \mathrm{L}$ for December and February and not detected for April and June; DRO, 9.155 $\pm 2.074,6.783 \pm 1.486$, $11.599 \pm 3.69$ and $21.213 \pm 5.762 \mathrm{mg} / \mathrm{L}$ for December, February, April and June respectively and lube oil range, $0.207 \pm 0.0115,2.171 \pm 0.339,3.948 \pm 0.9$ and $3.549 \pm 0.73 \mathrm{mg} / \mathrm{L}$ for December, February, April and June respectively. The average concentration values in the surface water of Kolo Creek obtained for the four months under study were GRO; $0.6898 \pm 0.0585 \mathrm{mg} / \mathrm{L}, \mathrm{DRO} ; 12.1875 \pm 3.2414 \mathrm{mg} / \mathrm{L}$ and lube oil range; $2.4688 \pm 0.4951 \mathrm{mg} / \mathrm{L}$.

The presence of total petroleum hydrocarbons categories on the surface water of Kolo Creek during the period of investigation were DRO > lube oil range > DRO. This indicated that both low and high molecular weight fractions were in the creek (George, 1994, Rauckyte et al., 2010). The low presence of the lower fractions of the petroleum categories in the creek may be as a result of strong wind, high temperature and high rate of evaporation associated with the creek (Daniel and Nna, 2016, Edori and Kpee, 2019). The lube oil range in the creek was also low, which may be an indication that the crude oil explored and produced along the coast of the creek possess little quantity of the higher category's fractions (Edori and Kpee, 2019). The resultant effect of hydrocarbons in the surface water affects the level of oxygen availability in the water, activities of micro organisms are reduced, fish breeding and spawning grounds are reduced and even the roots of trees in the mangrove are affected (Ugochukwu and Leton, 2004, Udo and Akpan, 2010).

The implication of high quantity of oil films present in the surface water is the reduction of the gaseous diffusion (oxygen deterioration) to the plants and animals that inhabit the aquatic environment (Osuji et al., 2004, Howard et al., 2009). Total petroleum hydrocarbons contamination in the surface water of any river causes damage to the ecological setting of the environment due to the carcinogenic, mutagenic and toxic nature of total petroleum hydrocarbons (Wang, 2011, Liu, et al., 2012, Sari et al., 2018). The presence of the diesel range organics in the surface water of the creek can lead to changes in the structure of species due to the high level of its toxicity can lead to changes in the structure of species due to the high level of its toxicity (Kurylenko and Izosimova, 2016), since long term exposure of organisms accumulates and transfers in the food chain processes thereby giving negative implications on aquatic organisms.

Table1. Concentrations of Total Petroleum Hydrocarbons Groups in the Surface Water of Kolo Creek in the Different Stations and Months

\begin{tabular}{|c|c|c|c|}
\hline Stations & Total Petroleum & Hydrocarbons & Groups \\
\hline & $\begin{array}{c}\text { Gasoline Range Organic } \\
(\mathrm{GRO}) \mathrm{C}_{6}-\mathrm{C}_{10}\end{array}$ & $\begin{array}{c}\text { Diesel Range Organic } \\
(\mathrm{DRO}) \mathrm{C}_{11}-\mathrm{C}_{28}\end{array}$ & Lube Oil Range $\mathrm{C}_{29}-\mathrm{C}_{40}$ \\
\hline 1 & - & $12.432 \pm 2.2963$ & $1.267 \pm 0.1244$ \\
\hline 2 & $1.148 \pm 0.031$ & $7.627 \pm 0.7836$ & $3.973 \pm 0.516$ \\
\hline 3 & $0.795 \pm 0.012$ & $15.375 \pm 3.2643$ & $2.165 \pm 0.5564$ \\
\hline Months & $1.228 \pm 0.074$ & $9.155 \pm 2.074$ & $0.207 \pm 0.0115$ \\
\hline December & $1.531 \pm 0.16$ & $6.783 \pm 1.486$ & $2.171 \pm 0.339$ \\
\hline February & - & $11.599 \pm 3.69$ & $3.948 \pm 0.9$ \\
\hline April & - & $21.213 \pm 5.762$ & $3.549 \pm 0.73$ \\
\hline June & & & \\
\hline
\end{tabular}

The results obtained for the concentrations of the three different categories of total petroleum hydrocarbons in the sediments of Kolo Creek are presented in Table 2. In Table 2, the concentration values recorded for the different hydrocarbon categories in the stations of Kolo Creek were, gasoline range organic (GRO); $1.9075 \pm 0.641,5.4995 \pm 2.036$ and $1.8961 \pm 0.196 \mathrm{mg} / \mathrm{Kg}$ for stations 1,2 and 3 respectively; diesel range organic (DRO); $32.83 \pm 9.573,30.2902 \pm 8.5931$ and $39.8561 \pm 11.0281 \mathrm{mg} / \mathrm{Kg}$ for stations 1, 2 and 3 respectively and lube oil range; $6.2071 \pm 1.43,3.4495 \pm 1.43$ and $0.5564 \pm 0.046$ $\mathrm{mg} / \mathrm{Kg}$ for stations 1,2 and 3 respectively. The concentration values obtained for total petroleum 
hydrocarbons categories in the sediment samples in the various stations of Kolo Creek were GRO; $3.0997 \pm 0.9577 \mathrm{mg} / \mathrm{Kg}$, DRO; $34.3254 \pm 9.7314 \mathrm{mg} / \mathrm{Kg}$ and lube oil range; $3.4043 \pm 0.8087 \mathrm{mg} / \mathrm{Kg}$. In the months under study, the obtained average concentration values for GRO were 8.2759 \pm 3.01 , $2.2904 \pm 0.811,1.5948 \pm 0.349$ and $0.2377 \pm 0.01 \mathrm{mg} / \mathrm{Kg}$ for December, February, April and June respectively; DRO, $51.2889 \pm 18.0216,23.1699 \pm 5.5295,28.4038 \pm 8.7521$ and $25.7765 \pm 5.8102 \mathrm{mg} / \mathrm{Kg}$ for December, February, April and June respectively and lube oil range, 9.7926 \pm 3.252 , not detected, $6.6589 \pm 0.6474$ and $7,4746 \pm 1.821 \mathrm{mg} / \mathrm{Kg}$ for December, February, April and June respectively. The average recorded concentration values in the sediments of Kolo Creek for the months under investigation were GRO; $3.0997 \pm 0.8087 \mathrm{mg} / \mathrm{Kg}, \mathrm{DRO} ; 34.3254 \pm 9.7314 \mathrm{mg} / \mathrm{Kg}$ and lube oil range; $5.9815 \pm 1.4301 \mathrm{mg} / \mathrm{Kg}$.

The effect of pollution and contamination of the sediments of the creek has negatively resulted in the ecosystem being altered. The activities of both legal and illegal oil production have rendered the sediments unfit for most bottom dwelling organisms and also the inhabitants of the area (Edori and Marcus, 2019). The functions of the membranes, impairments of organisms and their adaptive potentials, alterations in life processes and metabolic activities of bottom loving creatures are usually affected due to the retention of petroleum hydrocarbons in marine organisms (Capuzzo, 1985). The accumulation of hydrocarbon pollutants in the sediments is toxic to fish and other sediment loving organisms. The possible reduction in growth, species diversities, reproduction and decreased rate of survival of these organisms are as a result of oil contamination and pollution (Singare, et al., 2011, Onojake and Osuji, 2012). The release of diesel (DRO range fraction) into water resulted in the death of water animals and produced sharp reduction of species and also led to an increase in species that are tolerant to hydrocarbon pollution (Gublin-Green, 1990, Woke and Benson, 2018).

The hydrocarbons in the sediments are of utmost importance because they are easily absorbed to matter and settle to the bottom which is the reservoir for the accumulation of contaminants and pollutants. The information on the mode of contamination by the various categories of total petroleum hydrocarbons can be used to deduce the rate of anthropogenic influence and the source of contamination of the environment (Hostettler et al., 1999, Medeiros, et al., 2005, Lyla et al., 2012).

Table2. Concentrations of Total Petroleum Hydrocarbons Groups in the Sediments of Kolo Creek in the Different Stations and Months

\begin{tabular}{|c|c|c|c|}
\hline Stations & Total Petroleum & Hydrocarbons & Groups \\
\hline & $\begin{array}{c}\text { Gasoline Range Organic } \\
\left(\text { GRO) } \mathrm{C}_{6}-\mathrm{C}_{10}\right.\end{array}$ & $\begin{array}{c}\text { Diesel Range Organic } \\
(\mathrm{DRO}) \mathrm{C}_{11}-\mathrm{C}_{28}\end{array}$ & Lube Oil Range $\mathrm{C}_{29}-\mathrm{C}_{40}$ \\
\hline 1 & $1.9075 \pm 0.641$ & $32.83 \pm 9.573$ & $6.2071 \pm 1.43$ \\
\hline 2 & $5.4995 \pm 2.036$ & $30.2902 \pm 8.5931$ & $3.4495 \pm 1.43$ \\
\hline 3 & $1.8961 \pm 0.196$ & $39.8561 \pm 11.0281$ & $0.5564 \pm 0.046$ \\
\hline Months & $8.2759 \pm 3.01$ & $51.2889 \pm 18.0216$ & $9.7926 \pm 3.252$ \\
\hline December & $2.2904 \pm 0.811$ & $23.1699 \pm 5.5295$ & - \\
\hline February & $1.5948 \pm 0.349$ & $28.4038 \pm 8.7521$ & $6.6589 \pm 0.6474$ \\
\hline April & $0.2377 \pm 0.01$ & $25.7765 \pm 5.8102$ & $7,4746 \pm 1.821$ \\
\hline June & & & \\
\hline
\end{tabular}

The percentage concentrations of the various categories of total petroleum hydrocarbons in the surface water of Kolo Creek are shown in Table 3. The observation from Table 3 showed that the percentages of the different categories of total petroleum hydrocarbons of the surface water of the stations of Kolo Creek under investigation were GRO, 0.00, 9.09 and 4.34\% respectively for stations 1, 2 and 3; DRO, $90.75,59.70$ and $83.86 \%$ for stations 1,2 and 3 respectively and lube oil range, $9.25,31.21$ and $11.80 \%$ for stations 1, 2 and 3 respectively. The percentage values obtained for the surface water in the stations of Kolo Creek for the different hydrocarbon categories were GRO; $4.48 \% ; 78.10 \%$ and lube oil range; $17.42 \%$. The average percentage values obtained for the different stations were, GRO. $4.50 \%$, DRO, $78.10 \%$ and lube oil range, $17.40 \%$. In the months under investigation, the percentage concentration values obtained for the various total petroleum hydrocarbons categories investigated were for GRO; 11.60, $14.60 \%$ in December and February and $0.00 \%$ in the months of April and June, DRO; 86.45, 64.69, 74.61 and $85.67 \%$ for December, February, April and June respectively, lube oil range; 1.95, 20.71, 25.39 and 14.33\% for December, February, April and June respectively. The average percentage values recorded for the different categories in the surface water in the months under investigation in Kolo Creek were GRO; $6.55 \% ; 77.85 \%$ and lube oil range; $15.60 \%$. 
The true understanding of the actual nature, composition and the manner in which total petroleum hydrocarbons categories occur in the water surface in their proper percentages and proportions will give sound and adequate information on the pattern and nature of the pollution in the environment. A good and appropriate approach to tackle the remediation and restoration of a polluted river, creek or any water body is an understanding of the proper measure of the pattern, nature and mode of the of petroleum hydrocarbons involved in the pollution and the level of the petroleum hydrocarbon categories in the system. In the process of conducting a true risk-based analysis in a polluted site, there arises the necessity of detecting the range of hydrocarbons (carbon atoms present) and the level in which the different categories occur (TPHCWG, 1998), therefore the proper and appropriate method will then be used to attain the desired result. An adequate data provided for the hydrocarbon categories in the creek (GRO, DRO and lube oil) could help a manager of an oil ravaged river to evaluate the proper and actual conditions of the affected area (TNRCC, 2000), and efficiently offer better and more reliable techniques to restoring the polluted river or creek for the use of man other creatures in the environment.

Table3. Percentage Concentrations of Total Petroleum Hydrocarbons categories in the Surface Water of Kolo Creek in the Stations and Months

\begin{tabular}{|c|c|c|c|}
\hline Stations & Total Petroleum & Hydrocarbons & Groups \\
\hline & $\begin{array}{c}\text { Gasoline Range Organic } \\
\left(\text { GRO) } \mathrm{C}_{6}-\mathrm{C}_{10}\right.\end{array}$ & $\begin{array}{c}\text { Diesel Range Organic } \\
\text { (DRO) } \mathrm{C}_{11}-\mathrm{C}_{28}\end{array}$ & Lube Oil Range $\mathrm{C}_{29}-\mathrm{C}_{40}$ \\
\hline 1 & 0.00 & 90.75 & 9.25 \\
\hline 2 & 9.09 & 59.70 & 31.21 \\
\hline 3 & 4.34 & 83.86 & 11.80 \\
\hline Months & 11.60 & 86.45 & 1.95 \\
\hline December & 14.60 & 64.69 & 20.71 \\
\hline February & 0.00 & 74.61 & 14.33 \\
\hline April & 0.00 & 85.67 & 14.39 \\
\hline June & & & \\
\hline
\end{tabular}

The percentage concentrations values obtained for the various categories of total petroleum hydrocarbons in the sediments of Kolo Creek in the various stations and months under investigation are shown in Table 4. An observation from Table 4 showed that the percentage concentration values obtained for the various categories of total petroleum hydrocarbons in the sediments in the different stations of Kolo Creek were GRO; 4.66, 14.01 and 4.48 for stations 1, 2 and 3 respectively, DRO; 80.18, 77.20 and $94.20 \%$ for stations 1,2 and 3 respectively and lube oil range; $15.16,8.79$ and $1.32 \%$ for stations 1, 2 and 3 respectively. The average percentage concentration values obtained in the sediments of Kolo Creek in stations under study for the categories of total petroleum hydrocarbons were GRO; $7.72 \%$, DRO; $83.86 \%$ and lube oil range; $8.42 \%$. In the months under investigation, the observed average percentage concentration values for the various total petroleum hydrocarbons categories were for GRO; 11.93, 9.00, 4.35 and $0.71 \%$ for December, February, April and June respectively, DRO; 73.95, 91.95, 77.48 and $96.97 \%$ for the months of December, February, April and June respectively and lube oil range; $14.12,0.00,18.17$ and $22.32 \%$ for the sampled months of December, February, April and June respectively. The average percentage concentration values recorded in the sediments of Kolo Creek in months under study for the various categories of total petroleum hydrocarbons were GRO; $6.50 \%$, DRO; $79.85 \%$ and lube oil range; $13.65 \%$.

A clear understanding of the nature of hydrocarbon categories occurrence in the sediments of any water body is a veritable instrument in restoration and remediation processes and helps in providing a thorough evaluation of the sediment environment and quality clean-up strategy to be used (Douglas $e t$ al., (1991). The purge and trap or stripping methods can easily be adopted to recover the GRO group that contaminates the sediment because they are the most volatile (Rauckyte, 2010). Having a proper view on the pattern in which the sediment is contaminated by the various categories of total petroleum hydrocarbons and the mode of occurrence in the site will adequately help in thorough application of the technique applied for recovery and restoration of the contaminated site. The DRO group is less volatile, while the lube oil range volatility rate is very low because it is a semi-solid and has more stability in the system (sediments). In view of better understanding of the impact created by total petroleum hydrocarbons in the sediment environment, a true knowledge of the mode of occurrence of total petroleum hydrocarbons categories in the sediments of the creek is essential (Mohammadi et al, 2020). 
Table4. Percentage concentrations of Total Petroleum Hydrocarbons Categories in the Sediments of Kolo Creek in the Stations and Months

\begin{tabular}{|c|c|c|c|}
\hline Stations & Total Petroleum & Hydrocarbons & Groups \\
\hline & $\begin{array}{c}\text { Gasoline Range Organic } \\
\left(\text { GRO) } \mathrm{C}_{6}-\mathrm{C}_{10}\right.\end{array}$ & $\begin{array}{c}\text { Diesel Range Organic } \\
(\mathrm{DRO}) \mathrm{C}_{11}-\mathrm{C}_{28}\end{array}$ & Lube Oil Range $\mathrm{C}_{29}-\mathrm{C}_{40}$ \\
\hline 1 & 4.66 & 80.18 & 15.16 \\
\hline 2 & 14.01 & 77.20 & 8.97 \\
\hline 3 & 4.48 & 94.20 & 1.32 \\
\hline Months & 11.93 & & 14.12 \\
\hline December & 9.00 & 73.95 & 0.00 \\
\hline February & 4.35 & 91.00 & 18.17 \\
\hline April & 0.71 & 77.48 & 22.32 \\
\hline June & & 76.48 & \\
\hline
\end{tabular}

\section{CONCLUSION}

The study revealed that both the surface water and sediment samples of Kolo Creek were affected by total petroleum hydrocarbons contamination. The water environment of the creek is under threat and if unchecked will pose a lot of health challenges and issues to humans who make use of the creek for fishing and other recreational activities. The creek which also serve as the major source of water supply for the homes of the inhabitants need urgent attention and effort to mitigate the effect due to petroleum hydrocarbon pollution. The effect is great and unimaginable on the aquatic animals and plants that make use of the creek for daily living. The government and oil multinational companies in the area should take adequate steps to checkmate the rate of illegal oil activities within the creek and to an end the various illegal refining sites in the area. This can be achieved by empowering the indigenes of the area in proper oil business and not neglecting them in the crude oil business as it is today in Nigeria.

\section{REFERENCES}

[1] Agency for Toxic Substances and Disease Registry (ATSDR) (1999). Toxicological profile for petroleum hydrocarbons. Atlanta, GA, US Department of Health and Human Services, Public Health Service.

[2] Dambo, W. B. (1992). Tolerance of the periwinkles Pachymelania aurita (Muller) and Tympanotonus fuscatus (Linne) to refined oils. Environmental Pollution, 79; 293-296.

[3] Daniel, I. E. and Nna, P. J. (2016). Total petroleum hydrocarbon concentration in surface water of Cross River estuary, Niger Delta Nigeria. Asian Journal of Environment and Ecology, 1(2): 1-7.

[4] Douglas, G. S., McCarthy, K. J., Dahlen, D. T., Seavey, J. A., Steinhaur, W. G., Prince, R. C. and Elmendorf, D. L. (1991). The use of hydrocarbon analyses for environmental assessment and remediation, in contaminated soils: Diesel fuel contamination. Kostecki, P. T., Calabrese, E. J. (Eds.). FL, Lewis Publishers, Boca Raton.

[5] Capuzzo, J. M. (1985). Biological effects of petroleum hydrocarbons on marine organisms: Integration of experimental results and prediction of impacts. Marine Environmental Research, 17; 272-276. Doi 10.1016/0141.1136(85) 90104-7.

[6] Cortes, J. E., Suspes, A., Roa, S., González, C. \& Castro, H. E. (2012). Total Petroleum Hydrocarbons by Gas Chromatography in Colombian Waters and Soils. American Journal of Environmental Science, 8(4), 396-402.

[7] Edori, E. S. and Kpee, F. (2019). Total petroleum hydrocarbon concentration in surface water from Taylor Creek, Rivers State, Nigeria. Chemistry Research Journal, 4(5), 1-8.

[8] Edori, E. S. and Marcus A. C. (2019). Total petroleum hydrocarbons content of Taylor Creek, Rivers State, Niger Delta, Nigeria. International Journal of Advanced Research in Chemical Science, 6(12); 16-23.

[9] Emongore, V., Kealotswe, E., Sankwasa, S. and Keikanetswe, S. (2005). Pollution indicators in Gaborone industrial effluents. Journal of Applied Science, 5: 147-150.

[10] George, S. (1994). Bias associated with the use of EPA method 418.1 for the determination of total petroleum hydrocarbons in soils, in Hydrocarbon contaminated soils. Calabree, E. J., Kostecki, P. T. and Bonazountas, M. (Eds.). Chesea, Michigan, Lewis Publishers, volume 4 chapter 8; 115-142.

[11] Gublin-Green, C. O. (1990). The forminiferal fauna of Bonny Estuary, a baseline study NIOMR Technical Paper No. 64, 12-18.

[12] Hostettler, F. D., Pereira, W. E., Kvenvolden, K. A., Green, V. A., Luoma, S. N., Fuller, C. C. and Anima, R. (1999). A record of hydrocarbon input to San Francisco Bay as traced by biomarker profiles in surface sediment and sediment core. Marine Chemistry, 64; 115-127. 
[13] Howard, I. C., Gabriel, U. U. and Horsfall, M. (JNR) (2009). Evaluation of total hydrocarbon levels in some aquatic media in an oil polluted mangrove wetland in the Niger Delta. Applied Ecology and Environmental Research, 7(2), 111-120.

[14] Ikpe, E. E., Akpakpan, A. E., Nsi, E. W. and Ekanem, A. N. (2016). Determination of the level of petroleum hydrocarbon in water, fishes and plants from part of River Ethiope, Ogara in Delta State, Nigeria. International Journal for Research in Applied Chemistry, 2(8): 1-10.

[15] Ite, A. E. (2012). Biodegradation and ecotoxicity of petroleum-derived chemical wastes in the environment, Lancaster Environment Centre, Lancaster University

[16] Ite, A. E. and Ibok, U. J. (2013). Gas flaring and venting associated with petroleum exploration and production in the Nigeria's Niger Delta. American Journal of Environmental Protection, 1(4): 70-77.

[17] Ite. A. E., Ufot, U. F., Ite, M. U., Isaac, I. O. and Ibok, U. J. (2016). Petroleum industry in Nigeria: Environmental Issues, National Environmental Legislation and Implementation of International Environmental Law. American Journal of Environmental Protection, 4(1); 21-37.

[18] Kurylenko, V. and Izosimova, O. (2016). Study of the impact of petroleum hydrocarbons on Sea organisms. Journal of Ecological Engineering, 17(1): 26-29.

[19] Laboratory Analytical Work Instruction (LAWI), (2011). For the determination of total petroleum hydrocarbon in soil /sediment/sludge in Gas Chromatography. Published by Fugro (Nig). Ltd. 3:9.

[20] Lima, D., Santos, M. M., Ferreira, A. M. and Micaelo, C. R. (2008). The use of the Shanny lipophrys pholis for pollution monitoring, a new sentinel species for the northwestern European marine ecosystems. Environmental International, 34: 94-101.

[21] Linden, O. and Palsson, J. (2013). Oil contamination in Ogoni Land, Niger Delta. Ambio, 42(6): 685-710.

[22] Liu, J., Liu, G., Zhang, J., Yin, H. and Wang, R. (2012). Occurrence and risk assessment of polycyclic aromatic hydrocarbons in soil from the Tiefa Coal Mine District, Liaoning, China. China Journal of Environment Monitoring, 14(10); 2634-2642.

[23] Lyla, S., Manokaran, S. and Khan, A. (2012). Petroleum hydrocarbon distribution in continental shelf region of southeast coast of India. International Journal of Sediment Research, 27; 73-83

[24] Medeiros, P. M., Bicego, M. C., Castelao, R. M., Rosso, C. D., Fillmann, G. and Zambori, A. J. (2005). Natural and anthropogenic hydrocarbon inputs to sediments of Patos Lagoon estuary, Brazil. Environmental International Journal, 31: 77-87.

[25] Mohammadi, L., Rahdar, A., Bazrafshan, E. Dahmardeh, H., Susan, Md. A. B. H. and Kyzas, G. Z. (2020). Petroleum hydrocarbon removal from wastewaters: A Review. Processes, 8(44); 1-34.

[26] Moslen, M. and Miebaka, C.A. (2016). Temporal variations of heavy metal concentrations in Periopthalmus sp. obtained from Azuabie Creek in the Upper Bonny Estuary, Nigeria. Current Studies in Comparative Education, Science and Technology, 3(2); 136-147.

[27] Moslen, M. and Miebaka, C.A. (2017). Hydrocarbon contamination of sediments in the Niger Delta Region: A case study of the Azuabie Creek, upper reaches of the Bonny Estuary, Nigeria. Journal of Environmental Science, Toxicology and Food Technology, 11(9): 26-32.

[28] Nduka, J. K and Orisakwe, O. E. (2010). Water quality issues in the Niger Delta of Nigeria; Polyaromatic and straight chain hydrocarbons in some selected surface waters. Water Quality Exposure and Health, 2(2); 65-74.

[29] Nnadozie, K. (2003). K. (2003). Environmental regulation of the oil and gas industry in Nigeria. International Environmental Law and Policy in Africa. Chaytor, B. and Gray, K. R., eds. Dordrecht Springer Netherlands; 103-129.

[30] Onojake, M. C. and Osuji, L. C. (2012). Assessment of the physico-chemical properties of hydrocarbons contaminated soil. Achives of Applied Science Research, 4(1); 48-58.

[31] Osuji, L. C., Adesiyan, S. O. and Obute, G. C. (2004). Post impact assessment of oil pollution in Agbada west plain of Niger Delta, Nigeria: field reconnaissance and total extractable hydrocarbon content. Chemical Biodiversity, 1, 1569-1577.

[32] Rauckyte, T., Zak, S., Pawlak, Z. and Oloyede,A. (2010). Determination of oil and grease, total petroleum hydrocarbons and volatile aromatic compounds in soil and sediment samples. Journal of Environmental Engineering and Landscape Management, 18(3); 163-169.

[33] Sakari, M., Ting, I. S., Houng, I. Y., Lim, S. K. Tahir, R., Adnan, F. A. F., Yi, A. L. J., Soon, Z. Y, Hsia, B. S. and Shah, M. D. (2012). Urban effluent discharge into rivers, a forensic Chemistry approach to evaluate the environmental deterioration. World Applied Sciences Journal, 20(9); 1227-1235.

[34] Sari, G. L., Trihadiningrum, Y. and Ni'matuzahroh (2018). Petroleum hydrocarbon pollution in soil and surface water by public oil fields in Wonocolo Sub-district, Indonesia. Journal of Ecological Engineering, 19(2), 184-193. 
[35] Singare, P. U., Trivedi, M. P. and Misra, R. M. (2011). Assessing the physicochemical parameters of sediments ecosystem of Vasai Creek at Mumbai India. Marine Science, 1(1); 22-29.

[36] TNRCC (2000). Development of PCLs for total petroleum hydrocarbon mixture. Texas Natural Resources and Conservation Commission, Austin Texas.

[37] TPHCWG (1998). Analysis of petroleum hydrocarbons in environmental media. Total Petroleum Hydrocarbons Criteria Working Group Series, Volume 1, Amherst Scientific Publishers, Amherst. Massachusetts.

[38] Udoh, F. D. and Akpan M. N. (2010). Effect of oil spillage on Alakiri Community in Okirika Local Government area of Rivers State, Nigeria. Journal of Industrial Pollution Control,26(2): 139-143.

[39] Ugochukwu, C. N. C. and Leton, T. G. (2004). Environmental monitoring of an oil Servicing Company and its impact on the environment. AJEAM-RAGEE, 8, 27-30.

[40] Wang, Y., Jiang, F., Qia,xin, L., Xianguo, L., Xiaoyu, W. and Guoping, W. (2011). Effects of crude oil contamination on soil physical and chemical properties in Mamoge Wetland in China. China Geographical Sciences, 23(6); 708-715.

[41] Woke, G. N. and Benson, T. A. (2018). Impacts of petroleum hydrocarbon pollution on microbenthic fauna of Oluasiri River of Niger Delta. International Journal of Research in Agriculture and Forestry, 5(7): 2732.

Citation: EDORI, E. S., BEKEE, D., IGWE, P. U., “The Distribution of Total Petroleum Hydrocarbons Categories in Kolo Creek, Niger Delta, Nigeria", International Journal of Advanced Research in Chemical Science, 7(8), pp. 31-39. DOI: https:// doi.org/10.20431/2349-0403.0708004

Copyright: (c) 2020 Authors, this is an open-access article distributed under the terms of the Creative Commons Attribution License, which permits unrestricted use, distribution, and reproduction in any medium, provided the original author and source are credited. 